\title{
Análise da produção científica em orientação profissional: tendências e velhos problemas
}

\author{
FemandbHeniqueRerendeAguiar- UnivesidadedeBraślia, Braślia, Brasil \\ Maria Inês GanddfoConcição- UniveridadedeBraślia, Braślia, Brasil
}

\begin{abstract}
Resumo
O objetivo do presente artigo foi analisar as tendências científicas apontadas pela publicação em periódicos nacionais sobre o tema Orientação Vocacional, no período de 2006 a 2010. Procedeu-se a uma pesquisa bibliométrica com busca manual e boleana nas bases de dados BVS-Psi e IndexPSi, obtendo-se 108 artigos, que foram analisados quantitativa e qualitativamente. Verificou-se em que medida a produção em orientação vocacional tem atendido às agendas de pesquisa sugeridas por revisões anteriores e se a nomenclatura utilizada tornou-se mais concisa e homogênea. D entre os resultados, aponta-se: 1) que o número de artigos na área dobrou em relação aos cinco anos anteriores; 2) maior interação entre pesquisadores; 3) que houve mais estudos com populações diversas como aposentados e pessoas de baixa renda; 4) 0 avanço na área de testes psicológicos. O s resultados apontam que as agendas foram atendidas parcialmente e que houve um aumento na confusão a respeito da nomenclatura empregada.
\end{abstract}

Palavas have O rientação vocacional; Literatura (análise e critica); Pesquisa científica.

Analyses of the scientific production in vocational guidance: tendencies and old problems

\begin{abstract}
The objective was to analyze the scientific tendencies pointed by the national publications about Vocational Guidance from 2006 to 2010. A manual and boolean search was performed within the bases BVS-Psi and INDEX-Psi returning 108 articles, which were analyzed quantitatively and qualitatively. It was verified how much the production in vocational guidance has met the research agendas set by previous reviews and if the nomenclature used to refer to vocational guidance became more concise and homogeneous. From the results, it is pointed that 1) the number of articles in the field has doubled compared to the previous 5-year period; 2) there is more interaction among researchers; 3) there were more studies on other populations as retired people and low income groups; 4) there are more works about psychological tests. The results indicate that the agendas were partially met and there was increase in the confusion about the used nomenclature.
\end{abstract}

Keguads Vocational guidance; Literature (analysis and critics); Scientific research.

\section{Análisis de la producción científica en orientación profesional: tendencias y antiguos problemas}

\begin{abstract}
Resumen
El objetivo del presente artículo ha sido analizar las tendencias científicas señaladas por la publicación en periódicos nacionales sobre el tema Orientación Vocacional, en el período de 2006 a 2010. Se ha realizado una investigación bibliométrica con búsqueda manual y booleana en las bases de datos BVS-Psi e IndexPSi, obteniéndose 108 artículos, que han sido analizados cuantitativa y cualitativamente. Se ha verificado en qué medida la producción en orientación vocacional cumplía las agendas de investigación sugeridas por revisiones anteriores y si la nomenclatura utilizada se ha tornado más concisa y homogénea. Entre los resultados, se apunta: 1) que el número de artículos en el área se ha duplicado en relación a los cinco años anteriores, 2) mayor interacción entre investigadores; 3) que ha habido más estudios con poblaciones diversas como jubilados y personas de baja renta; 4) el avance en el área de testes psicológicos. Los resultados han apuntado que las agendas han sido cumplidas parcialmente y que ha habido un aumento en el lío por lo que respecta a la nomenclatura empleada.

Palabrasdave O rientación vocacional; Literatura (análisis y crítica); Investigación científica.
\end{abstract}

A orientação vocacional vem crescendo consideravelmente no cenário nacional (Teixeira, Lassance, Silva \& Bardagi, 2007) e internacional (Richard, 2005). Muito mais do que só abordar a transição da educação básica para o ensino superior, os trabalhos na área têm considerado temas diversos, como questões de gênero (Graf \& Diogo, 2009), populações em desvantagem socioeconômica (Paradiso \& Sarriera, 2009), aposentadoria (Costa \& Soares, 2010; Duarte \& Melo-Silva, 2009; Selig \& Valore, 2010), sujeitos com diagnóstico de psicose (Ribeiro, 2009), projeto de vida (Valore \& Viaro, 2007) e profissionais de áreas específicas, como bombeiros e militares (Natividade \& Brasil, 2006).
Em revisão realizada por Noronha e Ambiel (2006), foi feita a análise dos resumos referentes à produção científica em orientação vocacional no período de 1950 a 2005. A pesquisa foi feita nas bases eletrônicas BVS e IndexPsi, usando os termos: orientação profissional, orientação vocacional, interesses profissionais, escolha profissional e testes de interesse. Foram descartados teses, dissertaçoes, ensaios e artigos de outras áreas que não a psicologia. Nos artigos analisados $(\mathrm{n}=191)$, os autores encontraram uma preponderância de trabalho de autoria única (66\%) e aumento da produção científica, principalmente relatos de pesquisa, a partir da década de 1990. Destacou-se o aumento de trabalhos cujo 
toco era avaliar ou validar instrumentos como testes e escalas, a necessidade de mais pesquisas voltadas para populações específicas e a importância de aprofundar a investigação dos diversos construtos relativos aos processos de orientação.

Noronha e colaboradores (2006) analisaram a produção de teses e dissertações em orientação vocacional da década de 50 até 0 ano de 2005. Os autores usaram como unitermos: orientação profissional, orientação vocacional, testes de interesse, testes psicológicos e teste vocacional. Foi feita uma análise quantitativa e qualitativa dos trabalhos encontrados. 0 estudo também apontou para 0 aumento da produção a partir da década de 1990 e 0 principal público-alvo dos trabalhos foram professores, orientadores, pais e adolescentes. Os autores apontam que a construção e validação de instrumentos foram assuntos pouco abordados e que existe uma confusão conceitual na área, uma vez que muitos termos são usados para definir a orientação vocacional, realçando a necessidade de organização e definição clara dos termos utilizados e de maior aprofundamento teórico e metodológico.

Melo-Silva, Leal e Fracalozzi (2010) analisaram a produção científica em congressos brasileiros de orientação vocacional no período de 1999-2009. As autoras perceberam um crescimento de relatos de pesquisa e também de trabalhos em coautoria, apontando maior cooperação entre os pesquisadores brasileiros. Entretanto, notaram que ainda há 0 predomínio de trabalhos individuais. A população adolescente foi a mais estudada e o tema mais recorrente nos trabalhos foi escolha profissional na adolescência. Identificou-se também um interesse crescente nos trabalhos voltados para populações em situação de risco, como jovens institucionalizados e em desvantagem socioeconômica. Dentre as áreas apontadas como carecendo de mais atenção dos pesquisadores estão: políticas públicas e orientação vocacional, outras populações além dos adolescentes, jovens em situação de risco e avaliação dos serviços de orientação vocacional. As autoras criticam a qualidade da redação dos resumos, que em muitos momentos prejudicou a obtenção de dados para análise.

Em estudo abordando a produção científica da Rexista da ABOP (Associação Brasileira de O rientação Profissional), esta, que se tornou a Revista Brasilera de Orietação Prơissional, único periódico brasileiro especializado na área, Teixeira e colaboradores (2007) analisaram os artigos publicados desde 1997 até 2006 $(\mathrm{n}=85)$. Os principais resultados apresentam um aumento de artigos de pesquisa empírica e delineamento quantitativo, bem como de estudos com mais de um autor. Entretanto, há uma baixa colaboraçao entre pesquisadores de diferentes instituições, que, do contrário poderia enriquecer muito o conhecimento da área no âmbito nacional. Os autores apontam que há falta de delimitação teórica e conceitual nos estudos analisados e ponderam que, apesar da constatação de um aumento na quantidade de pesquisas, ainda há muito o que melhorar em qualidade e profundidade. Apontam ainda que, apesar do incremento na produção, a maior parte dos estudos são descritivos e mais revisões sistemáticas da literatura são necessárias.

Em revisão de literatura internacional, Nilsson e colaboradores (2007) avaliaram a produção científica em quatro periódicos publicados no EUA especializados na temática vocacional e de carreira. Foram considerados apenas artigos que reportassem estudos internacionais $(\mathrm{n}=376)$. Os autores encontraram, entre outros, que a maioria dos artigos eram empíricos $(79,8 \%)$ e com delineamento quantitativo. Os adultos trabalhadores foram a principal população-alvo dos estudos (37\%), seguida de estudantes do ensino médio (28,9\%) e dos universitários (19,3\%). Os principais temas abordados foram: 1) questões de carreira em populações, cultura e país específico; 2) atitudes vocacionais e acadêmicas, como satisfação e valores; 3) interesse e escolha de carreira; 4) características individuais e de personalidade; 5) desenvolvimento de carreira; 6) aconselhamento de carreira; além de outros 23 temas. O s autores destacaram a baixa presença de autores de países de outra língua que não o inglês e a necessidade de mais estudos com populações em desvantagem socioeconômica.

Entre os pesquisadores é de comum acordo que a análise da produção científica em áreas específicas do conhecimento, por meio de revisões sistemáticas da literatura e de pesquisa bibliométrica, é importante para 0 avanço do saber (Melo-Silva \& cols., 2010; Noronha \& Ambiel, 2006; Noronha \& cols., 2006). Segundo os autores, tal prática permite um olhar distanciado sobre o desenvolvimento científico da área, identificando lacunas e temas que requerem mais conhecimento científico e pesquisas. A área da orientação vocacional, atualmente em notável crescimento, se beneficia de estudos de revisão que apontem quais temas e assuntos requerem maior investimento por parte dos pesquisadores.

Em síntese, nas revisões da produção nacional percebe-se um aumento da produção científica na área, em sua maioria de artigos empíricos com delineamento quantitativo e de caráter descritivo. Os adolescentes são o principal população-alvo. Há um aumento no número de pesquisas com o objetivo de elaboração e validação de testes e escalas; entretanto, ainda há uma 
produção pequena na área. Em termos de número de autores, a predominância é de pesquisas de autoria única, mas com uma tendência à coautoria, inclusive entre pesquisadores de instituições distintas.

As agendas de pesquisa das revisões anteriores (Melo-Silva \& cols., 2010; Nilsson \& cols., 2007; Noronha \& Ambiel, 2006; Noronha \& cols., 2006) apontam a necessidade de: 1) mais estudos que abordem populações específicas, como pessoas institucionalizadas, em desvantagem socioeconômica e outras populações, além dos adolescentes; 2) trabalhos que prezem a coerência e 0 aprofundamento teórico dos construtos relacionados à orientação vocacional; 3) mais estudos que abordem a validação de instrumentos; 4) pesquisas que contemplem questões relativas às políticas públicas; 5) maior interação entre os pesquisadores, produzindo-se mais trabalhos em coautoria; e 6) definição conceitual clara da nomenclatura utilizada.

Além de analisar 0 estado da arte da publicação científica nacional sobre orientação vocacional, 0 presente estudo também teve por objetivo responder às seguintes questões de pesquisa: A produção científica em orientação vocacional dos últimos cinco anos atendeu às agendas de pesquisa indicadas por revisões de literatura anteriores? A nomenclatura utilizada para se referir ao processo de orientação vocacional se tomou mais concisa e homogênea?

\section{Método}

Realizou-se busca manual e pesquisa boleana nas bases de dados IndexPsi e BVS-Psi com os termos orientação, escolha, aconselhamento, profissional, vocacional, carreira, aposentadoria, nos anos de 2006 a 2010. Teses, dissertações, ensaios e resenhas não foram selecionados para análise. Considerou-se toda publicação em periódico nacional, mesmo quando se tratava de artigo com autoria internacional. A pesquisa limitou-se às publicações dos últimos cinco anos em periódicos nacionais, por já existirem outras revisões sistemáticas abarcando 0 período anterior. Foram encontrados 108 artigos que se adequavam aos critérios estabelecidos.

Procedeu-se à análise dos resumos e, quando necessário, do texto completo com o objetivo de extrair as informações de interesse para este estudo. Foi construída uma planilha de dados no Programa Excel, na qual foram tabuladas as informações e feita a análise de frequência. Para a criação das categorias de análise, buscou-se inspiração nos estudos de Noronha e Ambiel (2006) e Noronha e colaboradores (2006); entretanto, novas categorias foram criadas para abarcar as informações encontradas e os interesses de pesquisa.
Para cada artigo foram tabulados os seguintes dados: título do artigo, ano de publicação, nome do periódico, afiliação dos autores, número de autores, colaboração entre pesquisadores (número de artigos que continham autores de diferentes instituições), tipo de artigo (empírico, teórico ou relato de experiência), objetivo dos artigos (qualidade do processo, qualidade da técnica, qualidade do instrumento, população ou situação específica, correlacional, descritivo, revisão teórica, reflexão teórica), população-alvo, local de realização da pesquisa, testes/ instrumentos utilizados, palavras-chave e nomenclatura usada para se referir ao processo de orientação vocacional.

Os dados foram analisados quanto à frequência, com exceção das palavras-chave e da nomenclatura utilizada. As palavras-chave foram agrupadas em categorias por afinidade de sentido e analisadas qualitativamente na perspectiva da análise de conteúdo de Bardin (1977). Para a análise dos dados foram excluídos os títulos dos artigos e dos periódicos e os dados sobre local de realização da pesquisa, por não serem de interesse deste estudo. 0 detalhamento das categorias de análise será apresentado junto com os resultados.

\section{Resultados e discussão}

Os resultados dos 108 trabalhos analisados permitem, inicialmente, uma compreensão de que houve certa homogeneidade na distribuição quantitativa de artigos publicados anualmente no período de 2006 a 2010 (Tabela 1), com uma discreta tendência de aumento nos últimos anos. É possível afirmar que houve um considerável crescimento de publicações em relação aos cinco anos anteriores, uma vez que a quantidade dobrou em relação à apresentada por Noronha e Ambiel (2006), que apontaram 50 artigos publicados no período de 2000 a 2005.

A Tabela 2 expressa o número de autores em cada artigo. Percebe-se a preponderância de artigos com dois autores, representando metade das publicações na área. Os artigos de autoria única perfazem 20,4\% da amostra, $50 \%$ são artigos com dois autores, e os de autoria tripla, 17,6\%. Ao comparar com revisões anteriores, destaca-se uma mudança no padrão, com diminuição das produções com autoria única para a coautoria. Noronha e Ambiel (2006) encontraram prevalência de autoria única $(66 \%$ dos artigos analisados) e apenas 5,8\% de autoria tripla. A tendência apresentada por Teixeira e colaboradores (2007), de aumento de coautoria e diminuição da autoria única até 2006, parece prevalecer até 0 ano de 2010. 
Tabela 1. Distribuição por ano

\begin{tabular}{lcc}
\hline Ano & Frequência & Porcentagem \\
\hline 2006 & 20 & $18,5 \%$ \\
2007 & 20 & $18,5 \%$ \\
2008 & 21 & $19,4 \%$ \\
2009 & 23 & $21,3 \%$ \\
2010 & 24 & $22,2 \%$ \\
\hline Total & 108 & $100,0 \%$ \\
\hline
\end{tabular}

Tabela 2. Número de autores por artigo

\begin{tabular}{lcc}
\hline Número de autores & Frequência & Porcentagem \\
\hline 1 & 22 & $20,4 \%$ \\
2 & 54 & $50,0 \%$ \\
3 & 19 & $17,6 \%$ \\
4 & 10 & $9,3 \%$ \\
5 & 3 & $2,8 \%$ \\
\hline Total & 108 & $100,0 \%$ \\
\hline
\end{tabular}

Analisaram-se também os artigos em coautoria $(\mathrm{n}=86)$ com 0 intuito de verificar em quantos havia a presença de autores de instituições distintas. Foram considerados todos os artigos que tivessem pelo menos dois autores de diferentes filiações institucionais. Vinte e dois artigos $(25,5 \%)$ foram produzidos em parceria entre pesquisadores de diferentes instituições de ensino superior. Comparando estes resultados com os encontrados por Teixeira e colaboradores (2007) no período anterior, percebeu-se um pequeno aumento nesse indicador. A plumalidade de afiliações institucionais, associada ao aumento da coautoria, aponta uma tendência de maior integração e interação entre os pesquisadores que publicam na área de orientação vocacional no Brasil. Segundo Teixeira e colaboradores (2007), essas parcerias contribuem muito para a melhoria da qualidade teórico e técnica da orientação vocacional brasileira.

A Tabela 3 reúne todos os autores a partir da instituição de ensino à qual fazem parte. Os autores estrangeiros foram reunidos no item Intemacional e as instituições que apareceram apenas duas ou uma vez foram incluídas no item Outras Os dados apontam, assim como em outros estudos (Melo-Silva \& cols., 2010; Teixeira \& cols., 2007), maciça presença de autores da Universidade de São Paulo - USP de Ribeirão Preto $(\mathrm{n}=24)$, da Universidade Federal do Rio Grande do Sul - UFRGS $(\mathrm{n}=22)$ e da Universidade Federal de Santa Catarina - UFSC ( $\mathrm{n}=18)$. Entretanto, diferentemente de outras revisões sistemáticas da literatura, percebe-se uma grande quantidade de autores da Universidade São Francisco - USF (n=33), ocupando o primeiro lugar em número de autores. Também se destaca a grande presença de autores estrangeiros ( $\mathrm{n}=40)$, principalmente de Portugal $(\mathrm{n}=33)$.

Verificou-se uma preponderância de artigos empíricos (Tabela 4), representando 60,2\% da amostra, seguido de artigos teóricos e relatos de experiência. Dos artigos empíricos (Tabela 4), 53,8\% usou delineamento quantitativo, 36,9\% escolheu abordagem qualitativa e 9,2\% utilizou métodos mistos. Tais resultados estão em consonância com outros achados, internacionais e nacionais (Nilsson \& cols., 2007; Teixeira \& cols., 2007).

O estudo considerou oito categorias de análise: 1) descritivos incluiu (descrever ou caracterizar algo como expectativa na transição para 0 ensino médio ou para 0 mundo do trabalho ou estresse em pré-vestibulandos); 2) qualidade do instrumento (validar, normatizar ou construir algum instrumento); 3) reflexão teórica (articular ou discutir em nível teórico algum tema relacionado à orientação vocacional); 4) população ou situação específica (apresentava um trabalho restrito a um contexto, como pacientes com doença crônica, aposentados, psicóticos ou pessoas em desvantagem socioeconômica); 5) qualidade do processo (artigos que tinham por objetivo investigar a eficácia ou analisar 0 processo de orientação vocacional); 6) revisão de literatura; 7) correlacional (trabalhos que faziam correlação entre orientação vocacional e profissional e outros construtos como ansiedade, personalidade, etc.); e 8) qualidade técnica (apresentação ou análise de alguma técnica ou teoria específica). 
Tabela 3. Autores por afiliação institucional

\begin{tabular}{lcc}
\hline Afiliação & Frequência & Porcentagem \\
\hline USF & 33 & $13,7 \%$ \\
USP-Ribeirão & 24 & $10,0 \%$ \\
UFRGS & 22 & $9,1 \%$ \\
UFSC & 18 & $7,5 \%$ \\
USP & 14 & $5,8 \%$ \\
UFES & 11 & $4,6 \%$ \\
UFPR & 7 & $2,9 \%$ \\
UFU & 7 & $2,9 \%$ \\
UnB & 6 & $2,5 \%$ \\
Unisinos & 6 & $2,5 \%$ \\
Mackenzie & $5,1 \%$ \\
ULBRA & 5 & $2,1 \%$ \\
UFMG & 5 & $1,7 \%$ \\
PUC-Campinas & 4 & $1,2 \%$ \\
UEL & 3 & $1,2 \%$ \\
UFJF & 3 & $1,2 \%$ \\
UFLA & 3 & $1,2 \%$ \\
Outras & 3 & $11,2 \%$ \\
Internacional (Portugal, n=33) & 27 & $16,6 \%$ \\
\hline Total & 20 & $100,0 \%$ \\
\hline
\end{tabular}

Tabela 4. Tipo de artigo e delineamento da pesquisa empírica

\begin{tabular}{|c|c|c|c|c|c|}
\hline Tipo & Frequência & Porcentagem & D elineamento & Frequência & Porcentagem \\
\hline Empírico & 65 & $60,2 \%$ & Quantitativo & 35 & $53,8 \%$ \\
\hline Teórico & 29 & $26,9 \%$ & Qualitativo & 24 & $36,9 \%$ \\
\hline Relato & 14 & $13,0 \%$ & Misto & 6 & $9,2 \%$ \\
\hline Total & 108 & $100,0 \%$ & Total & 65 & $100,0 \%$ \\
\hline
\end{tabular}

A Tabela 5 apresenta a distribuição dos artigos de acordo com 0 objetivo. A maior parte dos artigos publicados no período tinha um objetivo descritivo (33\%), seguido dos artigos que buscaram validar, normatizar ou construir instrumentos $(14,8 \%)$ e dos artigos de reflexão teórica (13\%). Poucos artigos buscaram estudar técnicas específicas. Em sua maioria, os estudos eram reflexões com base em teorias, como a sistêmica, neorreichiana ou sócio-histórica. Também foram menos contemplados os estudos que buscavam analisar empiricamente construtos relativos ao processo de orientação vocacional e de carreira, como ansiedade, depressão, indecisão, etc.

Resultados semelhantes foram encontrados por Teixeira e colaboradores (2007) e Noronha e Ambiel (2006), que destacaram a importância da realização de mais estudos que buscassem um aprofundamento conceitual, teórico e metodológico. O destaque fica para 0 aumento de trabalhos com populações ou situações específicas, indicando uma ampliação da abrangência da orientação vocacional e de carreira para além dos adolescentes em momento de escolha do curso superior.

Houve um aumento nos estudos que se preocuparam em verificar a qualidade do processo de orientação vocacional. Foram produzidos $10 \mathrm{com}$ tal foco nos últimos cinco anos, contra 23 no período de 1950 a 2006 apontados pelos estudos de Noronha e Ambiel (2006). Ainda assim, há pouca publicação nacional com o intuito de verificar a eficácia dos trabalhos de orientação vocacional, principalmente a longo prazo, com a presença de fdlowưu 
Tabela 5. Artigos agrupados por categorias de objetivo

\begin{tabular}{lcc}
\hline Objetivo & Frequência & Porcentagem \\
\hline Descritivo & 36 & $33,3 \%$ \\
Qualidade do instrumento & 16 & $14,8 \%$ \\
Reflexão & 14 & $13,0 \%$ \\
Público espećífico & 11 & $10,2 \%$ \\
Qualidade do processo & 10 & $9,3 \%$ \\
Revisão & 9 & $8,3 \%$ \\
Correlacional & 7 & $6,5 \%$ \\
Qualidade da técnica & 5 & $4,6 \%$ \\
\hline Total & 108 & $100,0 \%$ \\
\hline
\end{tabular}

Vale ressaltar também 0 aumento de pesquisas sobre qualidade do instrumento. Em cinco anos produziu-se metade do que foi produzido com 0 mesmo objetivo em 55 anos (Noronha \& Ambiel, 2006), apontando a preocupação dos profissionais da área em obterem instrumentos de qualidade. Dentre esses artigos, os instrumentos mais estudados foram Questionário de Busca Autodirigida - SDS (20\%), Teste de Foto de Profissões - BBT-Br (12,5\%) e Escala de Aconselhamento Profissional - EAP $(12,5 \%)$. Outros instrumentos, dentro da área de orientação vocacional, que tiveram menor representatividade $(4,2 \%$ cada) foram: Inventário de Interesses Angelini, Autoeficácia na Transição para 0 Trabalho - AETT, Levantamento de Interesses Profissionais - LIP, Escala de Interesses Vocacionais -
EIV, Escala de Entrincheiramento na Carreira - EEC, Escala de Avaliação da Auto-eficácia para Atividades O cupacionais - EAAOc.

Ao analisar os dados da Tabela 6, que apresenta os instrumentos mais usados em pesquisas, aparece 0 SDS, o BBT-Br, a EAP e a Bateria de Prova de Raciocínio - BPR-5, sendo esses testes reconhecidos pelo Conselho Federal de Psicologia - CFP. A EAAOc não aparece na lista dos testes credenciados pelo CFP.

Percebe-se um aumento no número de instrumentos utilizados e aprovados pela entidade de classe quando comparamos com os resultados encontrados por Noronha e Ambiel (2006). O SD S só foi publicado em 2008 e a EAP recebeu parecer favorável do CFP em 2007, mostrando avanço na área de testes psicológicos para orientação vocacional.

Tabela 6. Frequência dos instrumentos usados em pesquisa

\begin{tabular}{lcc}
\hline Instrumento & Frequência & Porcentagem \\
\hline Questionário de Busca Autodirigida - SD S & 8 & $12,1 \%$ \\
Teste de Foto de Profissões - BBT-Br & 6 & $9,1 \%$ \\
Escala de Aconselhamento Profissional - EAP & 6 & $9,1 \%$ \\
Bateria de Prova de Raciocínio - BPR-5 & 3 & $4,5 \%$ \\
Escala de Avaliação da Autoeficácia para Atividades O cupacionais - EAAOc & 2 & $3,0 \%$ \\
Outros & 41 & $62,2 \%$ \\
\hline Total & 66 & $100,0 \%$ \\
\hline
\end{tabular}

Na Tabela 7 encontra-se a frequência com que diferentes populações foram contempladas nos estudos analisados. Os adolescentes do ensino médio foram a principal população-alvo das pesquisas em orientação vocacional, dado presente também em estudos anteriores (Melo-Silva \& cols., 2010; Teixeira \& cols., 2007). Por outro lado, diferente da revisão internacional de Nilsson e colaboradores (2007), os profissionais ficaram em terceim lugar. Mas tanto em Nilsson e colaboradores (2007) como em Melo-Silva e colaboradores (2010) e nos dados deste estudo, Estudantes do Ensino Médio, Universitários e
Profissionais são as três populações mais pesquisadas na área de orientação vocacional e de carreira.

Ainda que quantitativamente as outras populações não sejam muito expressivas, qualitativamente destacase a grande diversidade de populações estudadas. Podem-se citar como exemplo, os aposentados e pessoas em processo de aposentadoria, pessoas em situação de vulnerabilidade social e desvantagem socioeconômica, pessoas com necessidades educacionais especiais - PNEE, psicóticos, ex-usuários de serviços de orientação e outros.

Tal diversidade indica uma ampliação dos métodos e técnicas da orientação vocacional, de modo 
a abarcar outros sujeitos e suas especificidades. Entretanto, apareceram poucos trabalhos, por exemplo, com jovens do ensino fundamental, que desde essa fase já começam a apresentar angústia com a chegada do ensino médio e 0 processo de escolha vocacional (Aguiar \& Conceição, 2009). Apesar da diversificação da população-alvo, acredita-se que devam ser realizados mais estudos com tais segmentos no sentido de aprimorar 0 referencial teóricometodológico.

Tabela 7. População-alvo dos estudos

\begin{tabular}{lrr}
\hline Amostra & Frequência & Porcentagem \\
\hline Ensino médio & 32 & $35,6 \%$ \\
Universitários & 14 & $15,6 \%$ \\
Profissional & 12 & $13,3 \%$ \\
Usuários & 6 & $6,7 \%$ \\
Vulnerabilidade social & 4 & $4,4 \%$ \\
Aposentados & 3 & $3,3 \%$ \\
Ensino fundamental & 3 & $3,3 \%$ \\
PNEE & 3 & $3,3 \%$ \\
Pré-universitário & 3 & $3,3 \%$ \\
Escolas & 2 & $2,2 \%$ \\
Ex-usuánios & 2 & $2,2 \%$ \\
Formandos & 2 & $2,2 \%$ \\
Psicóticos & 2 & $2,2 \%$ \\
Doença crônica & 1 & $1,1 \%$ \\
Mulheres & 1 & $1,1 \%$ \\
\hline Total & 90 & $100,0 \%$ \\
\hline
\end{tabular}

\section{Análisequalitativa dos dados}

Com o intuito de responder às questões de pesquisa, buscou-se analisar qualitativamente a nomenclatura utilizada para se referir ao processo de orientação vocacional e as palavras-chave dos resumos.
No que diz respeito à nomenclatura, percebeu-se um uso de muitos termos para descrever processos semelhantes, sem haver o cuidado dos autores de apresentarem sustentação teórica adequada.

Tabela 8. Nomenclatura utilizada

\begin{tabular}{lc}
\hline Nomenclatura & Frequência \\
\hline D efinição vocacional & 1 \\
Escolha de carreira & 1 \\
Escolha profissional & 7 \\
Escolha vocacional & 1 \\
\hline Identidade profissional & 1 \\
Inclinação profissional & 1 \\
Interesse profissional & 1 \\
Interesse vocacional & 1 \\
\hline Desenvolvimento de carreira & 3 \\
Desenvolvimento profissional & 1 \\
Desenvolvimento vocacional & 4 \\
\hline Orientação de carreira & 1 \\
Orientação profissional - OP & 56 \\
O rientação profissional e vocacional - OP/ OV & 1 \\
Orientação profissional ocupacional & 1 \\
Orientação profissional vocacional - OPV & 3 \\
Orientação vocacional & 10 \\
Orientação vocacional ocupacional & 1 \\
\hline
\end{tabular}


A Tabela 8 foi organizada com base na proximidade de sentido entre as palavras utilizadas pelos autores. A confusão parece acontecer principalmente entre os termos vocacional, profissional e carreira. Em relação ao processo de orientação, foi encontrada a maior variedade de termos, sendo que os mais usados foram orientação profissional - OP e orientação vocacional - OV.

Como apontado por Noronha e Ambiel (2006) e Noronha e colaboradores (2006), há uma inconsistência na utilização dos termos na área da psicologia vocacional, indicando uma possível confusão teórica e uma falta de delimitação conceitual. O termo Cameira apareceu neste estudo, não tendo sido apresentado nas revisões anteriores.

Segundo Ribeiro (2011), o termo carreira vem sendo usado mais em âmbito internacional, enquanto no Brasil o termo orientação profissional é o mais frequente entre profissionais e pesquisadores. $\mathrm{O}$ autor defende 0 termo orientação profissional como mais adequado e afirma que as diferenças entre esses termos ficarão cada vez menos nítidas, uma vez que o campo da orientação vocacional se encontra em franco desenvolvimento em todo o mundo. Entretanto, ele destaca que o uso de uma determinada terminologia implica um conjunto de pressupostos e significados filosóficos que não devem ser ignorados.

É relevante e necessário para a área que os autores se preocupem com a compreensão adequada da nomenclatura utilizada e da ideologia subjacente a tais conceitos. Ainda que possa existir alguma diferenciação a partir da origem histórica de cada termo, atualmente eles vêm sendo usados como sinônimos.

As palavras-chave foram aglutinadas por aproximação de sentido com 0 intuito de identificar os principais temas explorados pelos estudos analisados. Vale lembrar que a frequência da palavra-chave não indica, necessariamente, a quantidade de artigos, já que um mesmo artigo pode usar mais de uma palavra-chave que se encaixe na mesma categoria, como orientação vocacional e orientação profissional, ambas na categoria orientação.

A categorização permitiu constatar algo muito importante quanto ao desenvolvimento científico. Há uma extensa variedade de palavras-chave utilizadas pelos autores, na maioria das vezes sem levar em consideração o Diđanáno de temindơja disponível no site da BVS-Psi (http:/ / www.bvs-psi.org.br). A título de exemplo, na categoria Orientação encontraram-se os termos: orientação, orientação profissional/ vocacional, orientação profissional, orientação vocacional, orientação ocupacional e orientação de carreira. 0 Diacnánio da biblicteca virtual emsaúde- Psicdoja - BVSPsi recomenda o uso do termo OrietaçãoV oaaional.
$\mathrm{Na}$ categoria Esclha, estavam presentes: escolhas vocacionais, escolha profissional e escolha de carreira. Para todos os casos, a BVS-Psi recomenda o termo eccha profissional. Tal confusão no uso de palavraschave corrobora a hipótese de confusão conceitual e prejudica 0 avanço científico, uma vez que dificulta a localização de artigos e a realização de revisões sistemáticas da literatura.

Em relação às palavras-chave, a categorização permitiu que se tivesse uma ideia dos temas que foram contemplados nos artigos. 0 total de 405 palavras foi distribuído em categorias por afinidade de sentido e a porcentagem de itens por categoria é expressa entre parênteses.

Orientação $(17,3 \%)$, Testes $(10,1 \%), \quad$ Addescênia $(4,7 \%)$ e Escolha $(7,4 \%)$ são temas clássicos na psicologia vocacional, que tradicionalmente se ocupou em orientar adolescentes em processo de escolha profissional utilizando testes e escalas. Também era esperado que tais palavras se destacassem por causa das palavras-chave usadas na busca em bases de dados. Aconsdhamento $(1,2 \%)$ se encaixaria na mesma categoria de orientação, mas se escolheu separá-lo para destacar a confusão conceitual. Destudvimato voacional (3,7\%), Trabalho e camera (3,7\%) e Interese voacional (3,5\%) também são três temas esperados quando se trata da psicologia vocacional, uma vez que abordam 0 processo de desenvolvimento do sujeito, as questões relativas ao mundo do trabalho e os interesses no processo de tomada de decisão.

$\mathrm{Na}$ categoria Construtos condatos $(3,5 \%)$ foram incluídas palavras como amizade, consciência, expectativa, exploração e inteligência. Idetidade $(2,2 \%)$, Pessonalidade (1\%), Maturidade (1\%), Autocicáaia (1\%), Indeisão $(0,7 \%)$, Inserção prơissional $(0,7 \%)$ e Comptênias vocaainais $(0,5 \%)$ são categorias de construtos correlatos que se destacaram por aparecerem com mais frequência, compondo uma categoria própria.

Abordagens ténicas (3,2\%) apontam artigos em que o eixo teórico foi relevante para a pesquisa, como por exemplo, estudos que buscavam relacionar a orientação vocacional com outras teorias ou aprofundamento teórico. Ciênia $(2,7 \%)$ se refere a palavras ligadas à produção científica, como metaciência, bibliometria, periódicos. Essas três categorias de análise apontam uma busca por aprofundamento teórico e científico dos pesquisadores, que pode auxiliar tanto na confusão conceitual como na qualidade das intervenções.

Saúde mental (2\%) considerou aqueles termos relacionados à saúde psicológica: bem-estar, estresse, qualidade de vida. Futuro (2\%) refere-se a palavras como planejamento de carreira e projeto de vida, indicando uma preocupação com o porvir. 
PNEE (2\%) identifica palavras que fizeram referência a pessoas com necessidades especiais, como síndrome de down. Em Socal (1,2\%) foram incluídas as palavras que se referiam a populações em situação de risco ou desvantagem social. As categorias Profissionais $(2,5 \%)$, Aposentadbria (0,7\%), Eduração supeior $(2,2 \%)$, Pais e família (1\%), PNEE e Social fazem referência às populações diversas abordadas nos estudos.

Gêneo(0,7\%), Vestibular (0,5\%) e Contemparaneidade $(0,7 \%)$ são temas relevantes para a psicologia vocacional, ao considerar como as questões da modernidade e de gênero influenciam o processo de desenvolvimento vocacional, e 0 vestibular, pelo seu papel significativo para a entrada no ensino superior. Avaliação de intevenção (1,2\%) e Eduração para cameira $(1,2 \%)$ revelam, respectivamente, a preocupação em avaliar as intervenções vocacionais e em propor programas que se preocupem com 0 desenvolvimento vocacional desde as primeiras fases escolares. As Outras $(10,1 \%)$ palavras-chave não se encaixaram adequadamente nas categorias propostas, portanto, foram classificadas juntas e consideradas de menor peso para a análise.

Vê-se uma grande quantidade de temas cobertos pelas publicações. D estaca-se um possível interesse dos estudiosos em aprofundar-se teoricamente nos construtos associados à orientação vocacional e uma tendência em pesquisas com populações diversas. Ressalta-se a necessidade de mais pesquisas que trabalhem com a população em processo de aposentadoria ou em desvantagem socioeconômica, bem como de artigos que incluam a dimensão de gênero e de educação para a carreira. O utra lacuna das publicações nacionais são artigos que visem avaliar a eficácia dos processos de orientação vocacional.

Não há menção de qualquer palavra associada às políticas públicas, o que não permite inferir que não houve algum estudo nesse âmbito. Entretanto, a partir do artigo de Melo-Silva e colaboradores (2010), que aponta a carência de trabalhos sobre políticas públicas em Congressos de Orientação Profissional, pode-se imaginar que a publicação em periódicos nessa área também é escassa. Isso permite refletir que a relação entre a orientação vocacional e as diversas políticas públicas é uma área que requer maior investimento científico para permitir maior disseminação das práticas de orientação.

\section{Considerações finais}

0 presente artigo pretendeu analisar a publicação nacional na área de orientação vocacional no período de 2006 a 2010. A partir da comparação dos resultados deste estudo com outras revisões disponíveis, principalmente aquelas que abarcam o período anterior ao analisado, foi possível responder às questões de pesquisa: 1) nos últimos cinco anos a produção em orientação vocacional atendeu às agendas de pesquisa indicadas por revisões de literatura anteriores? 2) A nomenclatura utilizada para se referir ao processo de orientação vocacional se tornou mais concisa e homogênea?

Em certa medida, as agendas de pesquisas indicadas por outras revisões foram contempladas, mas é necessário mais cuidado e atenção por parte dos pesquisadores. Não se sabe dizer se 0 aumento das pesquisas em diversas áreas e com diversas populações é realmente relevante, uma vez que houve um aumento geral na publicação acadêmica em orientação vocacional. De todo modo, é notável que mais estudos estão sendo realizados e isso, por si só, fala do crescimento científico da área.

Em relação aos itens atendidos vê-se: 1) um crescente interesse por estudos com populações diversas; 2) um aumento na produção científica e 3) em pesquisas que buscaram aprofundar construtos teóricos e avaliar instrumentos; e 4) aumento de trabalhos em coautoria.

Já os pontos que requerem maior atenção são: 1) aumento dos estudos com populações diversas, principalmente em desvantagem socioeconômica; 2) pesquisas que avaliem a eficácia dos serviços de orientação vocacional; 3) estudos que abordem as políticas públicas e a orientação vocacional; e 4) maior definição da nomenclatura utilizada.

Em relação à população-alvo, apesar da presença de estudos com outras populações, os adolescentes ainda lideram com grande diferença. Seria importante ampliar a produção com as demais populações-alvo, no intuito de equilibrar a distribuição por populações, principalmente aquelas em desvantagem socioeconômica que, historicamente, não foram muito contempladas em estudos nacionais ou internacionais (Nilsson \& cols., 2007; Teixeira \& cols., 2007).

Percebeu-se um grande aumento na produção científica quando comparada aos períodos anteriores e parece haver uma tendência a continuar 0 aumento. Se, por um lado, houve aumento no estudo de diversos construtos e na avaliação da qualidade dos instrumentos utilizados, por outro, continua muito maior a presença de artigos descritivos. Faltam estudos que avaliem a eficácia das intervenções e a questão das políticas públicas em orientação vocacional.

Vê-se um aumento da comunicação entre os pesquisadores brasileiros, inclusive de instituições de ensino superior distintas. Tal prática é muito positiva, uma vez que favorece 0 aumento da qualidade científica. Melo-Silva e colaboradores (2010) apontam 
essa prática como uma solução para cobrir a diversidade cultural do Brasil, sugerindo a realização de estudos comparativos entre sujeitos de diferentes estados.

Em relação à segunda pergunta, é notável que a confusão conceitual permanece. A nomenclatura utilizada foi considerada um ponto que necessita atenção urgente. Há uma grande diversidade nos termos, problema já identificado por Noronha e Ambiel (2006), há cinco anos atrás. Os resultados do presente estudo indicam não só a manutenção, mas um aumento dessa confusão, com a inclusão do termo camera como sinônimo de vocacional e profissional.

As revisões sistemáticas da literatura têm por objetivo contribuir para o crescimento de uma área do saber. Nesse sentido, o presente estudo pode contribuir para que os pesquisadores da área considerem as lacunas e inconsistências conceituais na área da psicologia vocacional e, dessa forma, aprimorem seus estudos e promovam novos avanços na área, Entendese que é vital para a ciência que os pesquisadores dialoguem entre si e com 0 conhecimento já produzido.

Resulta indiscutível a falta de clareza em relação à nomenclatura utilizada e acredita-se que este tema deva ser privilegiado em futuras pesquisas. Recomenda-se maior consideração quanto à avaliação dos serviços de orientação vocacional por parte dos pesquisadores e profissionais da área, bem como à interação com a questão das políticas públicas. Pesquisas com sujeitos diversos, como formandos e alunos de graduação e populações em desvantagem socioeconômica também contribuem para preencher lacunas da área e, assim, promover o desenvolvimento científico da orientação vocacional.

\section{Referências}

Aguiar, F. H. R., \& Conceição, M. I. G. (2009). Expectativas de futuro e escolha vocacional em estudantes na transição para 0 ensino médio. Revista Brasileira deOrientação Prơfissional, 10(2), 105115.

Bardin, L. (1977). Análise de contérdb Lisboa: Edições 70.

Costa, A. B., \& Soares, D. H. P. (2010). Orientação psicológica para a aposentadoria. Revista Psicdogja: Organizaçoes eTrabalho 9(2), 97-108.

Duarte, C. V., \& Melo-Silva, L. L. (2009). Expectativas diante da aposentadoria: um estudo de acompanhamento em momento de transição. Revista Brasilèra de Orientação Profissional, 10(1), 4554.
Graf, L. P., \& Diogo, M. F. (2009). Projeções juvenis: visões ocupacionais e marcas de gênero. Revista Brasilèra deOrietaçãoProfissional, 10(1), 71-82.

Melo-Silva, L. L., Leal, M. S., \& Fracalozzi, N. M. N. (2010). Produção científica em congressos brasileiros de orientação vocacional e profissional: período 1999-2009. Revista Brasileira de Orientação Profissional, 11(1), 107-120.

Natividade, M. R., \& Brasil, V. (2006). A escolha profissional entre os bombeiros militares. Reista Brasilèra deOriertaçãoProfissional, 7(1), 37-43.

Nilsson, J. E., Flores, L. Y., Berkel, L. V., Schale, C. L., Linnemeyer, R. M., \& Summer, I. (2007). International career articles: a content analysis of four journals across 34 years. Jaumal of Vocational Behavior, 70(3), 602-613. doi:10.1016/j.jvb.2007.01.003.

Noronha, A. P. P., \& Ambiel, R. A. M. (2006). Orientação profissional e vocacional: análise da produção científica. PsicoUSF, 11(1), 75-84.

Noronha, A. P. P., Andrade, R. G., Miguel, F. K., Nascimento, M. M., Nunes, M. F. O., Pacanaro, S. V., Ferruzzi, A. H., Sartori, F. A, Takahashi, L. T., \& Cozza, H. F. P. (2006). Análise de teses e dissertações em orientação profissional. Reiista Brasileira deOrietaçãoProfissianal, 7(2), 1-10.

Paradiso, A. C., \& Sarriera, J. C. (2009). Experiências ocupacionais no desenvolvimento de carreira de jovens trabalhadores. Revista Brasileira de Orientação Profissianal, 10(2), 93-104.

Ribeiro, M. A. (2009). O dispositivo grupal como estratégia de orientação profissional para pessoas em situação psicótica. Vínalo 6(1), 53-64.

Ribeiro, M. A. (2011). Orientação profissional: uma proposta de guia terminológico. Em M. A. Ribeiro \& L. L. Melo-Silva (O rogs.), Compêndio de cientação profissional edecamera: perspetivas histónicas e enfoques ténicos dássicos e modemos (vol. 1, pp. 23-66). São Paulo: Vetor.

Richard, G. V. (2005). International best practices in career development: review of the literature. Intemational Joumal for Educational and Vocational Guidance, 5(2), 189-201. doi:10.1007/ s10775-0058799-9.

Selig, G. A., \& Valore, L. A. (2010). Imagens da aposentadoria no discurso de pré-aposentados: subsídios para a orientação profissional. Cadamos de Psicdoja Social edoTrabalho 13(1), 73-87. 
Teixeira, M. A. P., Lassance, M. C. P., Silva, B. M. B., \& Bardagi, M. P. (2007). Produção científica em orientação profissional: uma análise da Revista Brasileira de Orientação Profissional. Reista Brasileira deOrietaçãoProfissional, 8(2), 25-40.

Valore, L. A., \& Viaro, R. V. (2007). Profissão e sociedade no Projeto de Vida de Adolescentes em O rientação Profissional. Reista Brasilera de OrientaçãoProfissional, 8(2), 57-70.

Recdidoem18/ 04/ 2011 Reformuladoem29/ 02/ 2012 Aprovadb em06/03/ 2012

Bolsistas da CAPES (Mestrado e Estágio Sênior).

Sobre os autores:

Femando Hennique Rezende Aguiar é psicólogo, Orientador Vocacional, Mestrando em Psicologia Clínica e Cultura pela Universidade de Brasília - UnB. Graduado e licenciado em Psicologia pela Universidade de Brasília e graduado em Core Energetics pelo Institute of Core Energetics/ New York - USA. A tua como psicoterapeuta corporal e orientador vocacional em atendimentos individuais e em grupo. Já realizou workshops internacionais (Israel) e regularmente apresenta trabalhos em congressos no exterior.

Maria Inês Gandolfo Conceição é psicóloga, psicodramatista didata supervisora, Doutora em Psicologia pela Universidade de Brasília (UnB), Professora Associada do Departamento de Psicologia do Instituto de Psicologia (DPCL/ IP/ UnB), Coordenadora do Laboratório de Família, Grupos e Comunidades (DPCL/ IP/ UnB), com Pós-doutorado na Universidade Federal Fluminense e na University of Toronto como Bolsista CAPES (Estágio Sênior).

Contato com os autores:

SGAS 915 Ed. Office Center - Bloco C - sala 303. CEP: 70390-000. Brasília-DF. Email: fhaguiar@gmail.com 